\title{
Evaluating Global Education at a Regional University: A Focus Group Research on Faculty Perspectives
}

\author{
Chin $\mathrm{Hu}^{1}$, Hooshang Pazaki ${ }^{2}$, and Erica Velander ${ }^{3}$
}

The main focus of this study is to assess students' level of global competency at a state university in the Northeast region of the United States. The three dimensions of global competency: global awareness, global citizenship and global competitiveness / cooperation are the main focus of this research. Based on a "snowball sampling method", a total of twelve faculty members who are full time professors at the university were selected and invited to participate in a focus group research to assess students' knowledge and skills in regards to global competency. The findings of this study suggest that many students do not possess sufficient information and knowledge related to the three dimensions of global competency. Faculty expressed concerns that students lack curiosity and motivation to explore global issues. The study discusses various cultural and institutional barriers that have thought to contribute to the insufficient level of global competency among students. [Article copies available for a fee from The Transformative Studies Institute. E-mail address: journal@transformativestudies.org Website: http://www.transformativestudies.org (C2014 by The Transformative Studies Institute. All rights reserved.]

KEYWORDS: Global Literacy, Global Awareness, Higher Education, Cultural Capital.

\footnotetext{
${ }^{1}$ Chin Hu, Ph.D., is Associate Professor of Sociology, Department of Sociology, Social Work \& Criminal Justice, East Stroudsburg University. Hu's teaching and research interests are in areas of globalization, comparison of societies, Chinese societies, and immigration studies. Address correspondence to: Chin Hu, 200 Prospect Street, East Stroudsburg, PA 18301; e-mail: chu@po-box.esu.edu.

${ }^{2}$ S. Hooshang Pazaki, Ph.D., is Professor of Sociology, Department of Sociology, Social Work \& Criminal Justice, East Stroudsburg University. Pazaki's teaching and research interests are in areas of cultural diversity, Muslim societies, and immigration studies.

${ }^{3}$ Erica Velander, graduate student, Department of History, East Stroudsburg University.
} 